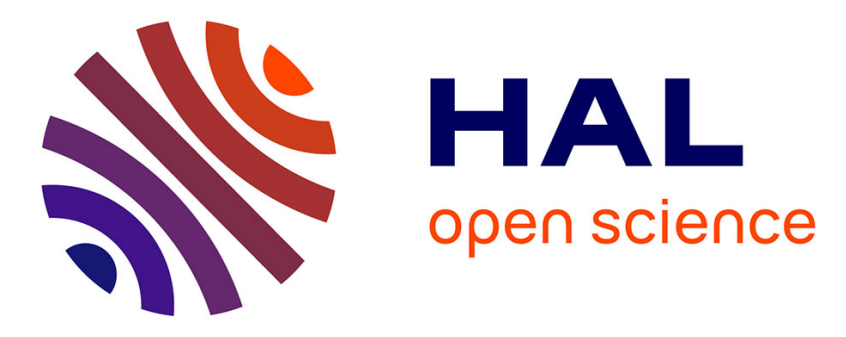

\title{
High-Level Behavior Regulation for Multi-Robot Systems
}

\author{
Martin Delecluse, Stephane Sanchez, Sylvain Cussat-Blanc, N. Schneider, \\ Jean-Baptiste Welcomme
}

\section{- To cite this version:}

Martin Delecluse, Stephane Sanchez, Sylvain Cussat-Blanc, N. Schneider, Jean-Baptiste Welcomme. High-Level Behavior Regulation for Multi-Robot Systems. Genetic and Evolutionary Computation COnference - GECCO 2014, Jul 2014, Vancouver, Canada. pp. 29-30, 10.1145/2598394.2598454 . hal-01136392

\section{HAL Id: hal-01136392 \\ https://hal.science/hal-01136392}

Submitted on 27 Mar 2015

HAL is a multi-disciplinary open access archive for the deposit and dissemination of scientific research documents, whether they are published or not. The documents may come from teaching and research institutions in France or abroad, or from public or private research centers.
L'archive ouverte pluridisciplinaire HAL, est destinée au dépôt et à la diffusion de documents scientifiques de niveau recherche, publiés ou non, émanant des établissements d'enseignement et de recherche français ou étrangers, des laboratoires publics ou privés. 


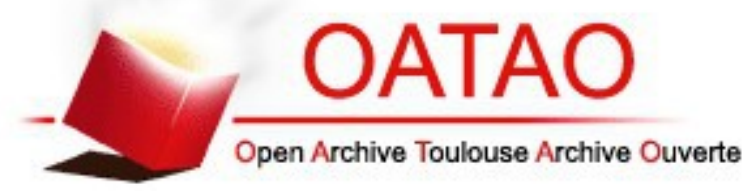

\section{Open Archive TOULOUSE Archive Ouverte (OATAO)}

OATAO is an open access repository that collects the work of Toulouse researchers and makes it freely available over the web where possible.

This is an author-deposited version published in : http://oatao.univ-toulouse.fr/ Eprints ID : 13054

To link to this article : DOI :10.1145/2598394.2598454

URL : http://dx.doi.org/10.1145/2598394.2598454

To cite this version : Delecluse, Martin and Sanchez, Stephane and Cussat-Blanc, Sylvain and Schneider, Nicolas and Welcomme, JeanBaptiste High-Level Behavior Regulation for Multi-Robot Systems. (2014) In: Genetic and Evolutionary Computation COnference GECCO 2014, 12 July 2014 - 16 July 2014 (Vancouver, Canada).

Any correspondance concerning this service should be sent to the repository administrator: staff-oatao@,listes-diff.inp-toulouse.fr 


\section{High-Level Behavior Regulation for Multi-Robot Systems}

\author{
Martin Delecluse, Stéphane Sanchez, \\ Sylvain Cussat-Blanc \\ University of Toulouse - IRIT - CNRS UMR 5505 \\ 2 rue du Doyen Gabriel Marty \\ 31042 Toulouse, France \\ martin.j.delecluse@gmail.com, \\ sanchez@irit.fr, cussat@irit.fr
}

\begin{abstract}
We propose a new collaborative guidance platform for a team of robots that should protect a fixed ground target from one or several threats. The team of robots performs high-level behaviors. These are hand-coded since they consist in driving the robots to some given position. However, deciding when and how to use these behaviors is much more challenging. Scripting high-level interception strategies is a complex problem and applicable to few specific application contexts. We propose to use a gene regulatory network to regulate high-level behaviors and to enable the emergence of efficient and robust interception strategies.
\end{abstract}

Keywords: Swarm robotics, Gene regulatory network, Behavior regulation

\section{INTRODUCTION}

Nowadays, technology development in the field of local network capabilities (communication network between several entities), may allow the implementation of new guidance schemes involving several cooperating platforms [4]. Future autonomous systems should evolve in complex context, continuous and dynamic environments: border control, firefighting, convoy protection, area surveillance, avalanche rescue, etc. and many other applications in which many heterogeneous entities should allocate resources and modulate behaviors depending on the on-going situation. We propose a new collaborative guidance platform for a team of robots that should protect a ground target from one or several threats by using bio-inspired approaches: Gene Regulatory Network (GRN) and evolutionary algorithms (EA).

We have designed a defense/interception mission in which a team of robots has to defend a target and intercept incoming threats. Multiple defending robots have to coordinate

\author{
Nicolas Schneider \\ Jean-Baptiste Welcomme \\ EADS Innovation Work \\ 18 rue Marius Terce \\ 31025 Toulouse, France \\ nicolas.schneider@airbus.com, \\ jean-baptiste.welcomme@airbus.com
}

their behavior with local information only (e.g. distance to the target to defend, to the next threat, to teammates, etc.) in order to intercept as much as possible threats coming sequentially or simultaneously from random position. The objective of the threats is to destroy the target. Because this study focuses on the defending robot behaviors, the threat behavior has been kept very simple: they are driving to the base at various speeds, following random checkpoints.

\section{BEHAVIORAL ARCHITECTURE}

The behavior architecture is based on a 3-layer structure: the top layer, named behavior layer, is a set of high-level behaviors that provides specialized functionalities to the robot; the intermediate layer, named control layer, is an aggregation layer, where all the decision taken by the high-level modules are regulated to generate the global behavior of the robot; the bottom layer, named actuation layer, is used to actuate the robot in the environment and to apply the actions generated by the upper layer.

Applied to our defense problem, the robots have access to four driving behaviors (top layer) which are: defense (drives to the target to defend), interception (drive to the threat), scattering (drive away from defending group gravity center) and grouping (drive to the gravity center). This architecture uses a GRN $[1,2]$ as behavior aggregator. GRN's have already been used to control multirobot systems [3] but are usually controlling the robot at a very low level: the GRN is generally directly plugged to the sensors and the actuators of the robots. In contrast, in our approach, the GRN weights each driving behaviors by the mean of one output protein per driving behavior.

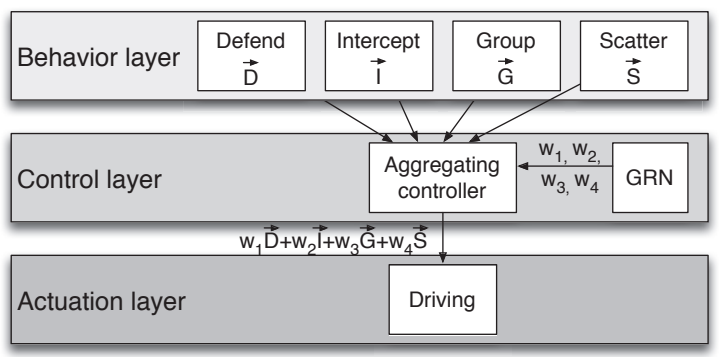

Figure 1: Integration of the behaviors and the GRN to the 3-layer behavioral architecture 


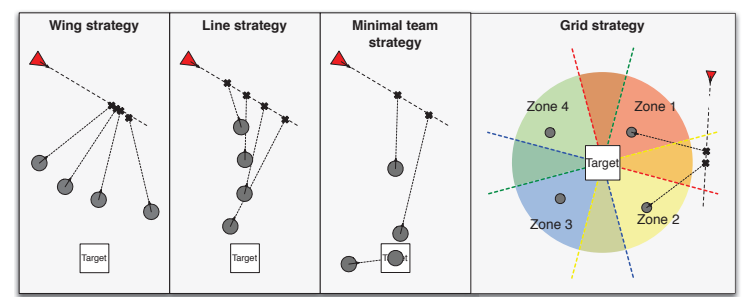

Figure 2: Strategies that emerge from independent trainings of the GRN.

To generate the driving direction, the GRN regulates the defending, intercepting, grouping and scattering behaviors by weighting the vectors generated by these behaviors. The final movement $\overrightarrow{F_{a}}$ of robot $a$ is given by $\overrightarrow{F_{a}}=w_{1} \overrightarrow{D_{a}}+w_{2} \overrightarrow{I_{a}}+$ $w_{3} \overrightarrow{G_{a}}+w_{4} \overrightarrow{S_{a}}$, where $\overrightarrow{D_{a}}$ (resp. $\overrightarrow{I_{a}}, \overrightarrow{G_{a}}$ and $\overrightarrow{S_{a}}$ ) is the vector provided by the defense (resp. interception, grouping and scattering) behavior. Each weigth $w_{i}$ is calculated with the concentration of four output protein: $w_{i}=\frac{c_{i}}{\sum_{j=1}^{4} c_{j}}$ where $c_{i}$ is the concentration of the protein associated to the weight $w_{i}$. Figure 1 depicts the use of a GRN to regulate the driving behavior of the defending robots.

\section{HANDLING A SEQUENCE OF THREATS}

In this experience, the robots have to coordinate there strategies in order to defend a target for a sequence of incoming threats. The threats are incoming sequentially in the environment from random positions. The complexity of the task also increases with the arrival of new threats: the speed of each new threat is increased so that it gets harder to intercept. Therefore, the main aim of this experience is to coordinate the defender team in order to intercept as much threats as possible and produce global stategies in order to intercept fast threats.

To tackle this problem, the GRN uses the following inputs: a robot-enemy distance morphogen, the robot/threat speed ratio, an enemy-target distance morphogen, an robot-allies distance morphogen, the team interception level (average level of interception of all the defending robots) and the position of the robot in the team according to there distances to the threat. These inputs allow each defender to evaluate their position in the team, their position relatively to the target to defend and to the threats and the dangerousness of the current threat. They provides the concentration of the GRN's input proteins.

A standard genetic algorithm is used to evolve the GRN. Each individual is evaluated on three random scenarios with a sequence of 100 threats. The speed of the threats linearly increase from $70 \%$ to $120 \%$ of the defender speeds. The fitness of a GRN is the sum of the fitnesses obtained on the three scenarios. Each scenario is evaluated by with a fitness function that takes into account the lifetime of the threat before interception. This function is designed to promote controllers that intercept the threats as far as possible from the target to defend.

The genetic algorithm is run 48 independent times in order to produce diverse team strategies. As presented in figure $2^{1}$, 4 mains strategies emerge: the minimal team strategy that

${ }^{1}$ Videos are available online: www.irit.fr/ Sylvain. Cussat-Blanc/Behavior_regulation/index_en.php

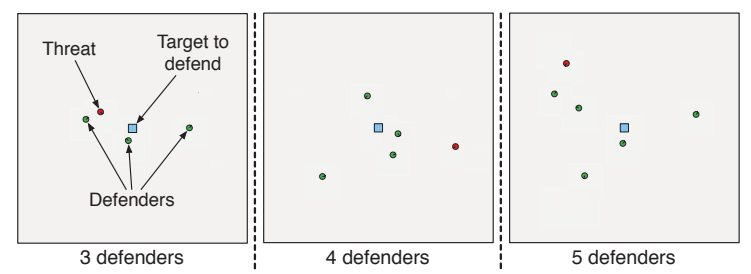

Figure 3: Example of system adaptation to the team size: the same GRN is used to handle teams composed of 3, 4 or 5 defenders. The team splits the environment according to the team size.

builds the minimal team to intercept the threats; the line strategy that positions the defenders along a line between the target to defend and the threat; the wing strategy that aligns the defenders along an orthogonal line between the threat and the target; and the grid strategy that divides the space into sectors and allocate a defender per sector.

Another property of the GRN approach is to be able to adapt the strategy to the size of the team with no further learning. Figure 3 shows this property on the grid strategies where the defenders modify there positions in the environnement according to the allies positions: the switch from a square to a triangle or a pentagon. Moreover the structure is twisted according to the position of the threat. Comparable observations can be made on the wing, the line and the minimal team strategies. This generalization on the number of defenders is inherent to the system because all the information used by a defender to take its decision (via the GRN) are local and relative. Therefore, defenders can be added or removed from the system without impacting the decision process. This team size adaptation can even be done during the simulation without perturbating the system.

\section{PERSPECTIVES}

We want to apply this approach to more complex problems that involve a team of heterogeneous units, several teams of equals units or several team of heterogeneous units. We also expect to continue this study about threats interception with an implementation of the method on real robots. According to our previous work on GRNs, we know that this approach is resistant to noise and could successfully apply to robotics but we need to precisely estimate the GRNs noise resistance and reality gap when applied to real-world problems.

\section{REFERENCES}

[1] S. Cussat-Blanc and J. Pollack. Using pictures to visualize the complexity of gene regulatory networks. In Artificial Life, volume 13, pages 491-498, 2012.

[2] S. Cussat-Blanc, S. Sanchez, and Y. Duthen. Controlling cooperative and conflicting continuous actions with a gene regulatory network. In Conference on Computational Intelligence in Games. IEEE, 2012.

[3] Y. Jin, H. Guo, and Y. Meng. A hierarchical gene regulatory network for adaptive multirobot pattern formation. Systems, Man, and Cybernetics, Part B: Cybernetics, IEEE Transactions on, 42(3), 2012.

[4] S. Le Ménec, K. Markham, A. Tsourdos, H.-S. Shin, and H. Piet-Lahanier. Cooperative allocation and guidance for air defence application. In World Congress, volume 18, pages 3897-3902, 2011. 